Article

\title{
Comparisons of the City Brand Influence of Global Cities: Word-Embedding Based Semantic Mining and Clustering Analysis on the Big Data of GDELT Global News Knowledge Graph
}

\author{
Chenyu Zheng \\ School of Journalism, Fudan University, Shanghai 200433, China; chenyuzheng@fudan.edu.cn
}

Received: 30 June 2020; Accepted: 30 July 2020; Published: 5 August 2020

check for updates

\begin{abstract}
Global cities act as influential hubs in the networked world. Their city brands, which are projected by the global news media, are becoming sustainable resources in various global competitions and cooperations. This study adopts the research paradigm of computational social science to assess and compare the city brand attention, positivity, and influence of ten Globalization and World Cities Research Network (GaWC) Alpha+ global cities, along with their dimensional structures, based on combining the cognitive and affective theoretical perspectives on the frameworks of the Anholt global city brand dimension system, the big data of global news knowledge graph in Google's Global Database of Events, Language, and Tone (GDELT), and the technologies of word-embedding semantic mining and clustering analysis. The empirical results show that the overall values and dimensional structures of city brand influence of global cities form distinct levels and clusters, respectively. Although global cities share a common structural characteristic of city brand influence of the dimensions of presence and potential being most prominent, Western and Eastern global cities differentiate in the clustering of dimensional structures of city brand attention, positivity, and influence. City brand attention is more important than city brand positivity in improving the city brand influence of global cities. The preferences of the global news media over global city brands fits the nature of global cities.
\end{abstract}

Keywords: global city; city brand influence; knowledge graph; semantic big data mining; GDELT

\section{Introduction}

Since the beginning of the 21st century, the processes of globalization and urbanization have been greatly accelerated. The influence of global cities on the economy, politics, culture, and society of the world increases every day. City brands are becoming the sustainable resources of global cities in their continuous competition for attracting people, capital, and goods all over the world. Global news media plays a vital role in constructing the city brand image of global cities. Facilitated by the web and the mobile Internet, the vast volume of global news articles covering global cities diffuse over both the physical and cyberspace of the world, shaping the cognition and attitude of the global audience toward global city brands. Previous research lacks assessment and comparison of global city brands that are projected by the global news media, while the full-sample big data of the global news knowledge graph in Google's Global Database of Events, Language, and Tone (GDELT) provides new opportunities to tackle this research question.

In this study, we followed the research paradigm of computational social science and compared the city brand influence of ten Globalization and World Cities Research Network (GaWC) Alpha+ global cites, as projected by the global news media. By combining the cognitive and affective theoretical perspectives on the global city brand dimension system proposed by Simon Anholt, we built an 
intelligent transforming and mapping method from the big data of the GDELT global news knowledge graph to the global city brands based on the technology of unsupervised machine learning. Specifically, we applied word-embedding semantic mining on the knowledge graph of related full-sample global news articles so as to quantitatively assess and compare the strengths and weaknesses of global cities' city brand attention, city brand positivity, and city brand influence projected by the global news media. After performing clustering analysis on the dimensional structures of global city brands, we also compared the dimensional structures of clusters of global city brands. Based on the empirical results, we finally discussed the preferences of the global news media in constructing the city brand image of global cities. We hope the conclusions of this research can provide references for the global city branding practice in terms of improving the attractiveness and influence of global cities.

\section{Literature Review}

\subsection{Conceptualization of Global City}

The term global city was coined by sociologist Saskia Sassen in 1991 [1]. At that time, three cities (i.e., New York, London, and Tokyo) had become the "command centers for the global economy". Global cities form "strategic transnational networks" and are the major driving force of "cross-border dynamics" that directly influence the political, economic, cultural, and societal climate of the world. There are various competitions between related cities, as they strive to join or remain in the set of global cities.

Research on ranking systems of global cities has been carried out for almost 30 years. Among various global city ranking systems, the Globalization and World Cities Research Network (GaWC) [2] is the most recognized. This ranking system follows the conceptualization of the global city proposed by Sassen and operationalizes the global city as a city that is a central node in the global network of four advanced producer services (i.e., accountancy, advertising, banking/finance, and law). Based on the centrality of each city, global cities are categorized into consecutive levels of Alpha, Beta, Gamma, high sufficiency, and sufficiency. Since 2000, GaWC has been publishing rankings of global cities every two to four years [3]. There are ten cities that have been categorized as Alpha+ global cities and above more than once in the last ten years, as shown in Table 1. In this study, we aimed to assess the city brands of these ten GaWC Alpha+ global cities.

Table 1. The GaWC Rankings of the Ten Alpha+ Global Cities [3].

\begin{tabular}{lllll}
\hline Global City & $\mathbf{2 0 1 0}$ & $\mathbf{2 0 1 2}$ & $\mathbf{2 0 1 6}$ & $\mathbf{2 0 1 8}$ \\
\hline London & Alpha++ & Alpha++ & Alpha++ & Alpha++ \\
New York & Alpha++ & Alpha++ & Alpha++ & Alpha++ \\
Paris & Alpha+ & Alpha+ & Alpha+ & Alpha+ \\
Singapore & Alpha+ & Alpha+ & Alpha+ & Alpha+ \\
Tokyo & Alpha+ & Alpha+ & Alpha+ & Alpha+ \\
Hong Kong & Alpha+ & Alpha+ & Alpha+ & Alpha+ \\
Shanghai & Alpha+ & Alpha+ & Alpha+ & Alpha+ \\
Dubai & Alpha+ & Alpha+ & Alpha+ & Alpha+ \\
Beijing & Alpha & Alpha+ & Alpha+ & Alpha+ \\
Sydney & Alpha+ & Alpha+ & Alpha & Alpha+ \\
\hline
\end{tabular}

\subsection{Competitive and Comparative Perspectives of City Branding}

The competition of city brands is one key aspect of various competitions among global cities. The research field of city branding [4] takes this competitive perspective arguing that globalization allows people, capital, and goods to move freely and conveniently across the world. As a result, cities around the world build their own city brands and compete with each other to improve their attractiveness to the workforce, residents, tourists, visitors, investment, and businesses [5]. By doing this, competitive goals, such as strategically providing sources of political, economic, and cultural 
value for the city [6], obtaining elements for generating wealth [7], boosting the local and domestic economy [8], and obtaining competitive advantages within and staying relevant to the global market [9] can be achieved. City branding research also normally takes a comparative perspective. Previous research prefers to compare city brands of different cities rather than focusing on the city brand of a single city[10-12]. In addition, most of the comparisons are conducted among cities from different countries [13].

\subsection{Construction of Global City Brands by Global News Media}

A city brand is constructed by various vital stakeholders, especially including the media [14]. After years of reflection [15], mainstream city branding research adapted the "co-creation branding paradigm" [16] in the 2010 decade. Researchers found that the increasing uncontrollability of city brands comes from the co-ownership [9] and co-management [17] of different stakeholder groups, which include residents, visitors, media, and so on. Researchers also discovered that the meanings of city brands are formed organically in the beginning [18], continuously evolve [19], and are constructed by different forces [20], which include first-hand experiences [21], interactions with the residents and word-of-mouth [17], events[22], and media [23]. Each of these forces independently construct city brands [24].

The media not only plays an important role in shaping public cognition toward city brands [25], but also effectively constructs the meanings of city brands [20]. As the world experiences the ages of the Internet of the 1980s, the Web of the 1990s, the mobile Internet of the 2000s, and artificial intelligence and social media of the 2010s, global news articles have been diffused through the web and the mobile Internet, and act as the information source in social networks. As a result, global news articles covering cities not only influence the local audience in the physical space, but also affect the global audience in cyberspace, and, in turn, construct city brands.

In previous research, there are few studies that assess the city brands of global cities based on the full-sample big data of global news articles. In this study, we focused on assessing the global city brands constructed by the global news media. We also performed comparisons among global city brands from the comparative perspective of global city branding.

\subsection{Cognitive and Affective Perspectives on the City Brand Dimension System}

City brands are normally assessed by constructing city brand indexes, which include the global city brand index [26] proposed by Simon Anholt, the European City Brand Barometer [27] proposed by Saffron, and so on. The core of city brand index research is the city brand dimension system. Previous research of city brand dimension systems includes the dimension systems of destination brand image [28], global city brand [26], resident satisfaction and commitment [29], city brand equity [30], city brand personality [31,32], and so on. Among them, the city brand dimension system of the Anholt global city brand index (i.e., Anholt city brand hexagon) is the most recognized and suitable for assessing the city brands of global cities in this study, since this index focuses on the image of well-known cities among the global audience [33].

There are six dimensions of Anholt's global city brand index:

1. Presence: the international status and standing of the city, including awareness of the city around the world, the volume of visits to the city, and the global contribution of the city in science, culture, and governance.

2. Place: the physical aspect of the city, including the pleasantness and the attractiveness of climate, environment, outdoors, and tours around the city.

3. Prerequisites: the basic conditions of the city, including affordable accommodations, the standard of public amenities, such as schools, hospitals, public transportation and infrastructure, and sports and cultural facilities. 
4. People: the friendliness, cultural diversity, and safety of the city, including the welcoming attitude of residents, the availability of communities of various languages and culture, and the degree of safety for people in the city.

5. Pulse: the interest and excitement of the city, including leisure and entertainment activities.

6. Potential: the economic and educational opportunities in the city, including the availability of jobs, suitability for business, and opportunities for obtaining higher education in the city.

Previous research mostly assesses city brand dimensions from both the cognitive perspective and the affective perspective [34-36]. The cognitive perspective of the city brand dimension system assesses the city brand in terms of the knowledge of and beliefs toward the city, while the affective perspective of the city brand dimension system assesses the city brand in terms of the attitudes and feelings toward the city. The city brands of global cities can be assessed comprehensively by combining both the cognitive and affective perspectives of the city brand dimension system. In this study, we constructed corresponding concepts of city brands based on the combination of cognitive and affective perspectives of Anholt's global city brand dimension system for assessing global city brands.

\subsection{Research Paradigm of Computational Social Science}

Previous research on city branding prefers qualitative methods over quantitative methods. According to Vuignier [37], 56\% of city branding research is qualitative, 22\% is quantitative, and the rest employs mixed or no research method at all. In this study, we followed the research paradigm of Computational Social Science (CSS) and conducted a quantitative assessment of global city brands.

CSS was proposed by Lazer et al. in 2009 [38]. It employs computational intelligence to analyze social big data to explore, explain, and predict the patterns of human behavior. There are three methodological pillars of computational social science, namely, big data mining, Agent-Based Social Simulation (ABSS), and large scale Internet experiments. In this study, we utilize the unsupervised machine learning based semantic mining methods on the big data of global media news.

\subsection{Big Data of GDELT Global News Knowledge Graph}

The knowledge graph consists of nodes and edges and it represents the knowledge in both nature and human society. In a knowledge graph, nodes represent entities, and edges connecting nodes represent the relationships between entities. The research on the knowledge graph dates back to 1956, when the concept of the semantic net [39] was constructed. The large scale application of knowledge graphs in both academia and industry started in 2012, when Google first applied this concept to its search engine[40]. Since then, social network platforms such as Facebook and Linkedin, e-commerce platforms, such as Amazon and eBay, and booking platforms, such as Uber and Airbnb, have all integrated knowledge graphs in their own products.

In the field of journalism and communication, Google's "Global Database of Events, Language, and Tone (GDELT)" project [41] started to construct the Global Knowledge Graph (GKG) of global media news in 2013. The GDELT project continuously crawls the web in order to obtain the full-sample big data of global news articles in various languages. The project continuously utilizes natural language processing technologies to automatically translate global news articles into English, extract entities (such as people, organizations, locations, themes, emotions, media outlets, events, etc.), along with their relationships, organizing both entities and relationships as records in the GKG. The GKG is continuously updated every $15 \mathrm{~min}$. and its annual volume exceeds 12 trillion bytes. From early 2015 to 30 October 2019, the GKG has accumulated one-billion global news articles. Journalism and communication research based on the big data of GKG is currently in its infancy, including the research on agenda setting [42] and fake news [43]. Hopp et al. [44] discovered that the GKG can be used to facilitate the fusion of theory-driven research (such as framing theory, news value theory, etc.) and big data driven research in the field of journalism and communication. In this study, we extracted entities 
of themes and emotions in the GKG records of global news articles covering ten GaWC Alpha+ global cities and utilized them as the big data materials for further mining.

\subsection{Word-Embedding Based Semantic Mining}

Word embedding translates words into corresponding high-dimensional word vectors by utilizing artificial neuron networks to perform unsupervised learning on the articles that contain these words [45]. The geometric relationships between word vectors in the high-dimensional space represent the semantic relationships between the corresponding words, similar words appear closely grouped, as do antonyms. The research method of word-embedding semantic mining has widely been applied to computational social science research, including research on semantic biases [46], gender and ethnic stereotypes [47], cultural sociology [48], and so on. However, it has not been applied to the field of city branding in terms of assessing global city brands.

\section{Research Design and Methods}

\subsection{Collecting the Big Data of GDELT Global News Knowledge Graph}

Based on the self-developed software module 1, we collected all of the GDELT GKG records from 2017 to 2019 related to ten GaWC Alpha+ global cities (i.e., London, New York, Paris, Tokyo, Hong Kong, Shanghai, Singapore, Dubai, Sydney, and Beijing). We determined that a GKG record is related to a global city if the record contains the name of that city.

Each GKG record contains cognitive and affective information of the corresponding global news article. In this study, we kept the theme list (the V1THEMES field in the GKG record), the positive emotion accumulation (the Positive Score of V1.5TONE field in the GKG record), and the negative emotion accumulation (the Negative Score of V1.5TONE field in the GKG record) information of every global news article. The theme list corresponds to the cognitive information of the article, while the positive emotion accumulation and the negative emotion accumulation correspond to the affective information of the article.

The theme list contains all of the themes in the article and has already been translated into English by GDELT. Both the positive emotion accumulation (Positive Score) and the negative emotion accumulation (Negative Score) are in the range of $[0,100]$. The value of the score represents the percentage of all words in the article that were found by GDELT to have a corresponding positive/negative emotional connotation. The higher the score, the more corresponding emotion the article contains.

We utilized the technology of unsupervised machine learning to mine the collected big data of the GDELT Global Knowledge Graph in order to assess global city brands. Specifically, this study adapted research methods of word-embedding semantic mining and clustering analysis, which are all based on the technology of unsupervised machine learning.

\subsection{Constructing the Concepts of City Brand Attention, Positivity, and Influence Based on Word-Embedding Semantic Mining}

Based on the combination of cognitive and affective theoretical perspectives on the Anholt's global city brand dimension system, we conceptualized city brand attention, city brand positivity, and city brand influence, along with their corresponding dimensions of global cities, and we operationalized these concepts by constructing a word-embedding semantic mining research method on the big data of GDELT GKG records. By doing this, the values of city brand attention, positivity, and influence, along with their corresponding dimensions of global cities, can be empirically assessed. These values can then be utilized in order to capture the strengths and weaknesses, dimensional structures, and cluster characteristics of global city brands. 


\subsubsection{City Brand Attention}

The conceptualization of city brand attention takes the cognitive theoretical perspective of city brands. The city brand attention measures the attention of global news media put on a global city brand and its dimensions. It captures the city brand awareness of every global city.

The construction of the dimensions of city brand attention takes the theoretical framework of Anholt's global city brand dimension system. In other words, the global city brand attention contains six dimensions, including (1) presence attention, (2) place attention, (3) prerequisites attention, (4) people attention, (5) pulse attention, and (6) potential attention.

In this study, city brand attention of global cities is operationalized as the sum of projection from all of the related themes to each dimension in the high-dimensional word-embedding semantic space. The higher the value of city brand attention, the higher the awareness is of a global city brand.

\subsubsection{City Brand Positivity}

The conceptualization of city brand positivity takes the affective theoretical perspective of city brands. The city brand positivity measures the attitude of global news media toward a global city brand and its dimensions. It captures the city brand reputation of every global city.

The construction of the dimensions of city brand positivity also takes the theoretical framework of Anholt's global city brand dimension system. In other words, the city brand positivity contains six dimensions, including (1) presence positivity, (2) place positivity, (3) prerequisites positivity, (4) people positivity, (5) pulse positivity, and (6) potential positivity.

In this study, the city brand positivity of global cities is operationalized as the ratio of the sum of projection from positive emotion accumulations brought by all of the related themes to each dimension, to the sum of projection from negative emotion accumulations brought by all of the related themes to each dimension in the high-dimensional semantic space of word vectors. The higher the value of city brand positivity, the more positive the reputation of the city brand. If the value of city brand positivity is larger than 1 , then it means that the positive emotion accumulations are larger than the negative emotion accumulations, and vice versa.

\subsubsection{City Brand Influence}

The conceptualization of city brand influence takes the theoretical perspective of combining the cognitive and affective components of city brands. The city brand influence measures the product of city brand attention and city brand positivity. It captures city brand influence as constructed by the global news media. It represents the media image strength of city brands as well. It also reveals the competitiveness of a city brand's media image.

The construction of city brand influence dimensions again takes the theoretical framework of Anholt's global city brand dimension system. In other words, the city brand influence contains six dimensions, including (1) presence influence, (2) place influence, (3) prerequisites influence, (4) people influence, (5) pulse influence, and (6) potential influence.

In this study, the city brand influence of global cities is operationalized as the product of corresponding city brand attention and city brand positivity. The higher the value of city brand influence, the more influential the global city brand.

\subsubsection{Word-Embedding Semantic Mining on GDELT Global News Knowledge Graph}

Based on the self-developed software module 2, we calculated the city brand attention, positivity, and influence, along with their corresponding six dimensions from 2017 to 2019 for each of ten GaWC Alpha+ global cities. The calculations were based on the above conceptualizations and operationalizations and they were implemented by applying the word-embedding semantic mining to the collected big data of GDELT GKG records. The entire semantic mining procedure is described, as follows: 


\section{(1) Calculate the average word vectors for all of the GKG themes and city brand dimensions}

The names of GKG themes and the descriptions of city brand dimensions contain corresponding keywords. We first retrieved the corresponding 300-dimensional word vectors for keywords of each GKG theme and each city brand dimension from the "GoogleNews-vectors-negative300" word2vec model, which was pre-trained by Google [45]. Afterwards, we calculated the algorithmic mean of these word vectors for these keywords to obtain the average word vector that represents the semantic meaning of the corresponding GKG theme and city brand dimension.

\section{(2) Assign related GKG themes to their corresponding city brand dimensions}

We first obtained the semantic similarity between each pair of GKG theme and city brand dimension by calculating the cosine similarity of their corresponding average word vectors. Geometrically speaking, this cosine similarity represents the unit projection from the theme average word vector to the dimension average word vector in the 300-dimensional semantic space. We assigned a GKG theme to a particular city brand dimension only if the corresponding cosine similarity was greater than zero and was the largest among all six city brand dimensions. The reliability and validity of assessing the similarity of the semantic meaning of concepts based on the cosine similarity of their the average word vectors of corresponding keywords has already been proven by Garten et al. [49].

\section{(3) Calculate the city brand attention, positivity, and influence of global cities iteratively}

For each GKG record covering a global city, we iterated through its theme list. For each GKG theme, we added the value 1, the Positive Score of this record, and the Negative Score of this record to the attention value, the positive emotion accumulation, and the negative emotion accumulation of a city brand dimension, respectively, if the theme could be assigned to that dimension. By iterating through all of the GKG records of global news articles, we obtained the sum of city brand attention, positive emotion accumulations, and negative emotion accumulations for each dimension of every global city.

The overall city brand attention for each global city was obtained by adding the values of all six dimensions of city brand attention. All of the values of the overall and the six dimensions of city brand attention for every global city were divided by the maximum dimensional value of city brand attention among all of the global cities. By doing this, all of the dimensional values of city brand attention were mapped to the range of $[0,1]$. This does not affect the final results of city brand influence for comparison among global cities, but makes the values of both the city brand attention and the city brand influence more friendly to interpretation.

The values of all six dimensions of city brand positivity for each global city were obtained by dividing the corresponding dimensional positive emotion accumulations with the negative emotion accumulations. The overall city brand positivity for each global city was obtained by dividing the sum of positive emotion accumulations in all six dimensions with the sum of negative emotion accumulations in all six dimensions.

The values of all six dimensions of city brand influence for each global city were obtained by multiplying the corresponding dimensional value of city brand attention with city brand positivity. Additionally, the overall city brand influence for each global city was obtained by multiplying the corresponding value of overall city brand attention with overall city brand influence.

\subsection{Clustering Analysis of the Global City Brands Based on Unsupervised Machine Learning}

Based on the classic K-Means unsupervised machine learning algorithm, we performed clustering analysis on the six-dimensional structures (i.e., presence, place, prerequisites, people, and pulse) of global cities in three aspects of city brands (i.e., city brand attention, city brand positivity, and city brand influence). In each aspect, global cities were automatically clustered by the K-Means algorithm. Global cities with similar six-dimensional structures were placed in the same cluster, while global cities 
with very different six-dimensional structures were placed in different clusters. We then performed comparisons of structural characteristics among clusters of global cities.

Specifically, for each aspect of city brands (i.e., city brand attention, positivity, and influence), we first normalized the six-dimensional vector of each global city (i.e., the vector consisting of the city brand dimensional values of presence, place, prerequisites, people, and pulse) based on the 12 norm. By doing this, all six-dimensional vectors of global cities were scaled to the same length of 1 (i.e., the sum of squares of normalized dimensional values is 1). Additionally, the resulting unit vectors of global cities can be used to compare the structural characteristics of city brands on the same scale. We utilized the K-Means algorithm to cluster global cities based on their unit vectors, and then assessed the structural characteristics of different clusters of global cities based on their corresponding unit vectors of cluster centers. In order to find the optimal clustering results, we chose the K-Means++ [50] algorithm in order to select initial cluster centers for the K-Means clustering algorithm.

\section{Results}

\subsection{Numbers of Global News Articles Covering Global Cities}

This study collected all of the GDELT GKG records of global news articles covering ten GaWC Alpha+ global cities (i.e., London, New York, Paris, Singapore, Tokyo, Hong Kong, Shanghai, Dubai, Beijing, and Sydney) from 2017 to 2019. The total size of the corresponding GKG records is 28.639 GB, which describe 29,608,153 global news articles. We performed word-embedding semantic mining and clustering analysis based on the technology of unsupervised machine learning on this collected full-sample dataset in order to assess and compare the city brand attention, positivity, and influence of these global cities.

Based on the number of related global news articles, ten global cities are ranked in a descending order as follows: London (9,035,815 articles), New York (8,119,397 articles), Paris (2,626,556 articles), Beijing (2,341,324 articles), Sydney (1,574,101 articles), Singapore (1,549,763 articles), Dubai (1,213,053 articles), Tokyo (1,175,845 articles), Hong Kong (1,119,537 articles), and Shanghai(852,762 articles). The numbers of related global news articles show a skewed distribution (Shapiro-Wilk test $p<0.001$ ).

There is a huge gap in terms of numbers of related global news articles among global cities, as shown in Figure 1. The difference between London, which has the highest number, and Shanghai, which has the lowest, is about 8.18 million. This value exceeds the number of global news articles covering any global city except London.

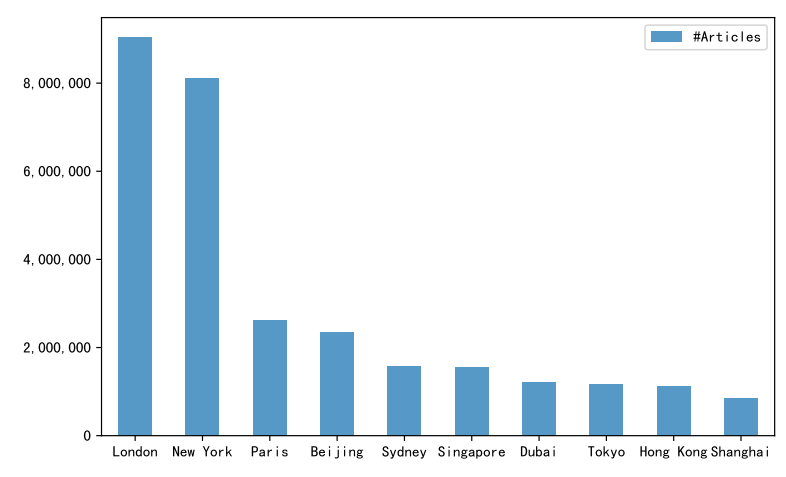

Figure 1. Numbers of Global News Articles.

\subsection{City Brand Attention of Global Cities}

As shown in Table 2, the differences among values of global city brand attention from 2017 to 2019 not only reflect the cognitive preferences of global news media over city brands of global cities, but also demonstrate the different city brand awareness of global cities. 
Based on the overall values of global city brand attention, ten GaWC Alpha+ global cities are ranked in descending order, as follows: New York, London, Paris, Beijing, Singapore, Hong Kong, Tokyo, Sydney, Dubai, and Shanghai.

Judging from the six-dimensional values of global city brand attention (Figure 2a), all of the six-dimensional structures of global cities share a common characteristic: there are significant differences among different dimensions of global city brand attention (one-way ANOVA $\mathrm{F}(5,54)=3.988, p<0.005$, as shown in Table 3). Specifically, (1) the dimension of presence is the most prominent, followed by the dimension of potential; (2) the dimensions of place, people, and prerequisites are medium; and, (3) the dimension of pulse is relatively low.

Table 2. City Brand Attention of Global Cities.

\begin{tabular}{lllllll}
\hline Presence Attention & Place Attention & Prerequisites Attention & People Attention & Pulse Attention & Potential Attention & City Brand Attention \\
\hline New York 1.0000 & New York 0.3792 & New York 0.2896 & New York 0.3243 & New York 0.1530 & New York 0.6901 & New York 2.8363 \\
London 0.7398 & London 0.2738 & London 0.2133 & London 0.2209 & London 0.1270 & London 0.5439 & London 2.1187 \\
Beijing 0.3592 & Paris 0.1456 & Paris 0.0858 & Paris 0.0946 & Paris 0.0565 & Beijing 0.2523 & Paris 0.9351 \\
Paris 0.3328 & Beijing 0.1020 & Beijing 0.0732 & Beijing 0.0804 & Beijing 0.0375 & Paris 0.2198 & Beijing 0.9047 \\
Singapore 0.1942 & Singapore 0.0630 & Singapore 0.0473 & Singapore 0.0531 & Singapore 0.0228 & Singapore 0.1594 & Singapore 0.5399 \\
Hong Kong 0.1477 & Sydney 0.0525 & Sydney 0.0397 & Sydney 0.0466 & Sydney 0.0203 & Hong Kong 0.1210 & Hong Kong 0.4156 \\
Tokyo 0.1399 & Hong Kong 0.0491 & Hong Kong 0.0378 & Hong Kong 0.0417 & Hong Kong 0.0185 & Dubai 0.1101 & Tokyo 0.3806 \\
Dubai 0.1241 & Dubai 0.0472 & Dubai 0.0367 & Tokyo 0.0362 & Dubai 0.0182 & Tokyo 0.1098 & Sydney 0.3799 \\
Sydney 0.1216 & Tokyo 0.0438 & Tokyo 0.0328 & Dubai 0.0334 & Tokyo 0.0182 & Sydney 0.0992 & Dubai 0.3698 \\
Shanghai 0.0978 & Shanghai 0.0318 & Shanghai 0.0229 & Shanghai 0.0285 & Shanghai 0.0119 & Shanghai 0.0929 & Shanghai 0.2859 \\
\hline
\end{tabular}

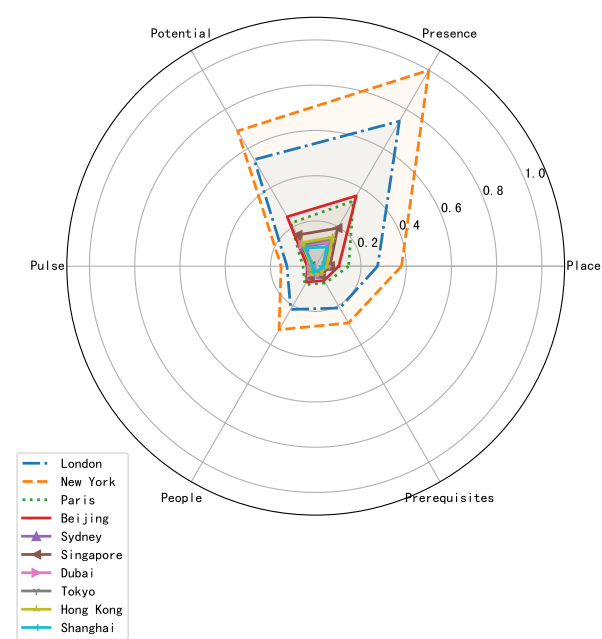

(a)

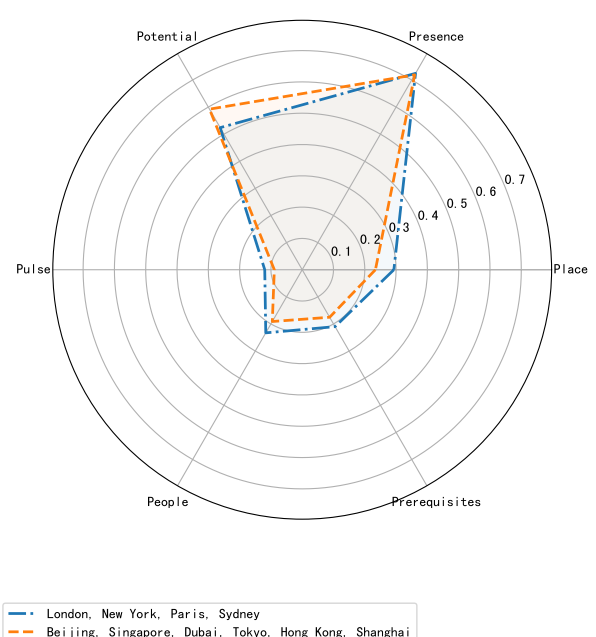

(b)

Figure 2. Dimensional Structures of City Brand Attention. (a) Dimensional Structures of Global Cities; (b) Dimensional Structures of Cluster Centers.

Table 3. one-way ANOVA of City Brand Attention Dimensions.

\begin{tabular}{ccccc}
\hline & sum_sq & df & F & PR(>F) \\
\hline C(Dimension) & 0.569734 & 5.0 & 3.987565 & 0.003764 \\
Residual & 1.543078 & 54.0 & & \\
\hline
\end{tabular}

After performing the 12-norm-based normalization on the six-dimensional vectors of city brand attention for each global city and applying the K-Means algorithm to the corresponding normalized unit vectors, the ten global cities were automatically divided into two clusters that were based on their structural characteristics captured by the unit vectors. The best $\mathrm{K}$ (the number of clusters) is 2 , and the sum of squared distances to the closest cluster center (inertia) is 0.024 . Cluster 1 contains London, New York, Paris, and Sydney, while cluster 2 contains Beijing, Singapore, Dubai, Tokyo, Hong Kong, and Shanghai. 
The structural characteristics of city brand attention clusters are captured by the unit vectors of cluster centers (Figure 2b): (1) the global cities in cluster 1 have relatively higher normalized values in the city brand attention dimensions of place, people, prerequisites, and pulse; (2) the global cities in cluster 2 have relatively higher normalized values in the city brand attention dimension of potential; while, (3) both cluster centers have similar normalized value in the city brand attention dimension of presence.

\subsection{City Brand Positivity of Global Cities}

As shown in Table 4, the differences among values of global city brand positivity from 2017 to 2019 not only reflect the affective preferences of global news media over city brands of global cities, but also demonstrate the different city brand reputation of global cities.

Based on the overall values of global city brand positivity, ten GaWC Alpha+ global cities are ranked in descending order, as follows: Singapore, Dubai, Shanghai, Sydney, London, Tokyo, New York, Hong Kong, Paris, and Beijing. The differences among overall city brand positivity values of global cities are small. In addition, as a common characteristic, their values are all below 1 , which means that the sum of the negative emotion accumulations is higher than the sum of the positive emotion accumulations of global cities.

Table 4. City Brand Positivity of Global Cities.

\begin{tabular}{|c|c|c|c|c|c|c|}
\hline Presence Positivity & Place Positivity & Prerequisites Positivity & People Positivity & Pulse Positivity & Potential Positivity & City Brand Positivity \\
\hline Singapore 0.7374 & ingapore 0.7867 & Singapore 0.7954 & Dubai 0.8758 & Shanghai 0.7131 & Dubai 0.8336 & Singapore 0.7730 \\
\hline Shanghai 0.7173 & Shanghai 0.7779 & ai 0.7869 & Singapore 0.8231 & ore 0.7069 & Singapore 0.8003 & Dub \\
\hline Dubai 0.6979 & Dubai 0.7499 & 7867 & Shanghai 0.7648 & & & Shanghai 0.7372 \\
\hline 0.6344 & Sydney 0.6744 & 0.6678 & $\mathrm{~s}$ & 0.6957 & Syd & 0.6695 \\
\hline London 0.6064 & London 0.6520 & London 0.6343 & London 0.6985 & New York 0.6546 & London 0.6758 & n 0.6471 \\
\hline Tokyo 0.5972 & Tokyo 0.6451 & Tokyo 0.6154 & Tokyo 0.6658 & Dubai 0.6538 & Tokyo 0.6273 & Tokyo 0.6209 \\
\hline New York 0.5735 & New York 0.6280 & $\mathrm{rk} 0611$ & New York 0.6496 & .6354 & New York 0.6198 & New York 0.6083 \\
\hline Paris 0.5529 & Hong Kong 0.5908 & Hong Kong 0.5583 & Paris 0.6315 & Paris 0.6013 & Hong Kong 0.6193 & Hong Kong 0.5799 \\
\hline Beijing 0.5424 & Paris 0.5754 & Paris 0.5564 & Hong Kong 0.6275 & Hong Kong 0.5835 & Paris 0.5908 & Paris 0.5760 \\
\hline Hong Kong 0.5410 & Beijing 0.5507 & Beijing 0.5372 & Beijing 0.5683 & Beijing 0.5301 & Beijing 0.5671 & Beijing 0.5513 \\
\hline
\end{tabular}

Based on the overall values of global city brand positivity, ten GaWC Alpha+ global cities are ranked in descending order, as follows: Singapore, Dubai, Shanghai, Sydney, London, Tokyo, New York, Hong Kong, Paris, and Beijing. The differences among overall city brand positivity values of global cities are small. In addition, as a common characteristic, their values are all below 1 , which means that the sum of the negative emotion accumulations is higher than the sum of the positive emotion accumulations of global cities.

Judging from the six-dimensional values of global city brand positivity (Figure 3a), all of the six-dimensional structures of global cities have a common characteristic: differences among different dimensions are not significant (one-way ANOVA $\mathrm{F}(5,54)=1.037, p>0.05$, as shown in Table 5). The global city brand positivity is relatively balanced across six dimensions.

After performing the 12-norm-based normalization on the six-dimensional vectors of city brand positivity for each global city and applying the K-Means algorithm to the corresponding normalized unit vectors, ten global cities are automatically divided into three clusters that are based on their structural characteristics captured by the unit vectors. The best $K$ (the number of clusters) is 3 and the sum of squared distances to the closest cluster center (inertia) is 0.003 . Cluster 1 contains London, New York, Paris, Sydney, Tokyo, and Hong Kong; cluster 2 contains Beijing, Singapore, and Shanghai; and, cluster 3 contains Dubai.

The structural characteristics of city brand positivity clusters are captured by the unit vectors of cluster centers (Figure 3b): (1) there is little difference among all of the three clusters in terms of the city brand positivity dimensions of presence, place, and prerequisites; (2) cluster 3 has relatively higher normalized values in the city brand positivity dimensions of potential and people; and, (3) in the dimension of pulse, the normalized values of cluster 1 , cluster 2 , and cluster 3 are in descending order. 


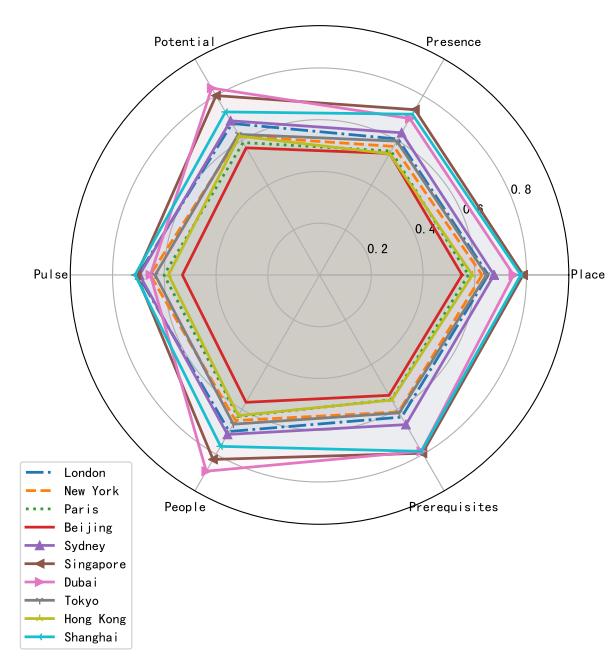

(a)

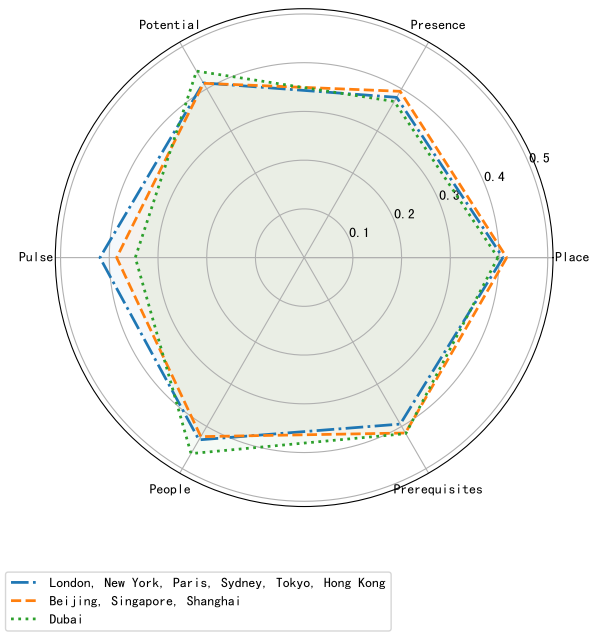

(b)

Figure 3. Dimensional Structures of City Brand Positivity. (a) Dimensional Structures of Global Cities (b) Dimensional Structures of Cluster Centers.

Table 5. One-way ANOVA of City Brand Positivity Dimensions.

\begin{tabular}{ccccc}
\hline & sum_sq & df & F & PR(>F) \\
\hline C(Dimension) & 0.037428 & 5.0 & 1.037492 & 0.405202 \\
Residual & 0.389616 & 54.0 & & \\
\hline
\end{tabular}

\subsection{City Brand Influence of Global Cities}

The differences among values of global city brand influence from 2017 to 2019 not only reflect the global city brands constructed by global news media based on the fusion of its cognitive and affective preferences, but also demonstrate the comprehensive influence of global city brands based on both their attention and positivity, as shown in Table 6.

Table 6. City Brand Influence of Global Cities.

\begin{tabular}{|c|c|c|c|c|c|c|}
\hline Presence Influence & Place Influence & Prerequisites Influence & People Influence & Pulse Influence & Potential Influence & City Brand Influence \\
\hline New York 0.5735 & New York 0.2381 & New York 0.1770 & New York 0.2107 & New York 0.1001 & New York 0.4278 & New York 1.7255 \\
\hline Beijing 0.1949 & Paris 0.0838 & Paris 0.0478 & Paris 0.0598 & Paris 0.0340 & Beijing 0.1431 & Paris 0.5386 \\
\hline Singapore 0.1432 & Singapore 0.0496 & Singapore 0.0377 & Singapore 0.0437 & Singapore 0.0161 & Singapore 0.1276 & Singapore 0.4174 \\
\hline Dubai 0.0866 & Sydney 0.0354 & Dubai 0.0289 & Sydney 0.0331 & Sydney 0.0141 & Dubai 0.0918 & Dubai 0.2823 \\
\hline Tokyo 0.0835 & Dubai 0.0354 & Sydney 0.0265 & Dubai 0.0293 & Dubai 0.0119 & Hong Kong 0.0749 & Sydney 0.2543 \\
\hline Hong Kong 0.0799 & Hong Kong 0.029 & Hong Kong 0.0211 & Hong Kong 0.0261 & Tokyo 0.0116 & Tokyo 0.0689 & Hong Kong 0.2410 \\
\hline
\end{tabular}

Based on the overall values of global city brand influence, ten GaWC Alpha+ global cities are ranked in descending order, as follows: New York, London, Paris, Beijing, Singapore, Dubai, Sydney, Hong Kong, Tokyo, and Shanghai. There are huge gaps between different global cities in terms of their overall city brand influence. Specifically, ten global cities form three levels: New York and London in the first level; Paris, Beijing, and Singapore in the second level; and, Dubai, Sydney, Hong Kong, Tokyo, and Shanghai in the third level.

Judging from the six-dimensional values of global city brand influence (Figure 4a), all of the six-dimensional structures of global cities share a common characteristic: there are significant differences among different dimensions of global city brand influence (one-way ANOVA $\mathrm{F}(5,54)=3.992, p<0.005$, as shown in Table 7). Specifically, (1) the dimension of presence is 
the most prominent followed by the dimension of potential; (2) the dimensions of place, people, and prerequisites are medium; while, (3) the dimension of pulse is relatively low.

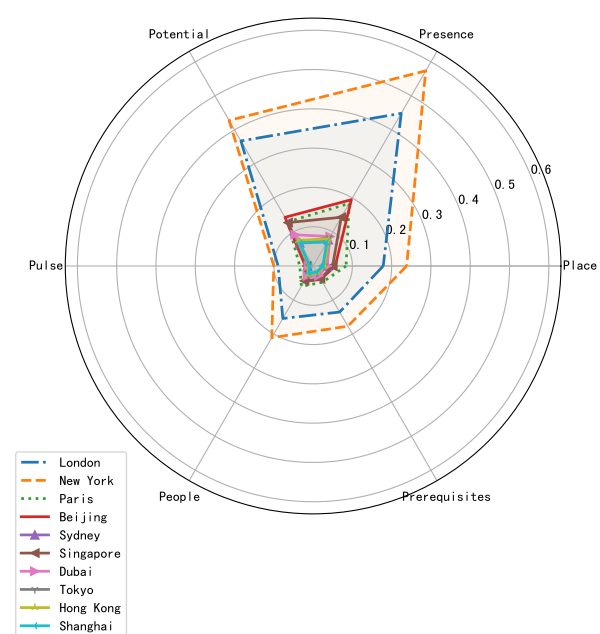

(a)

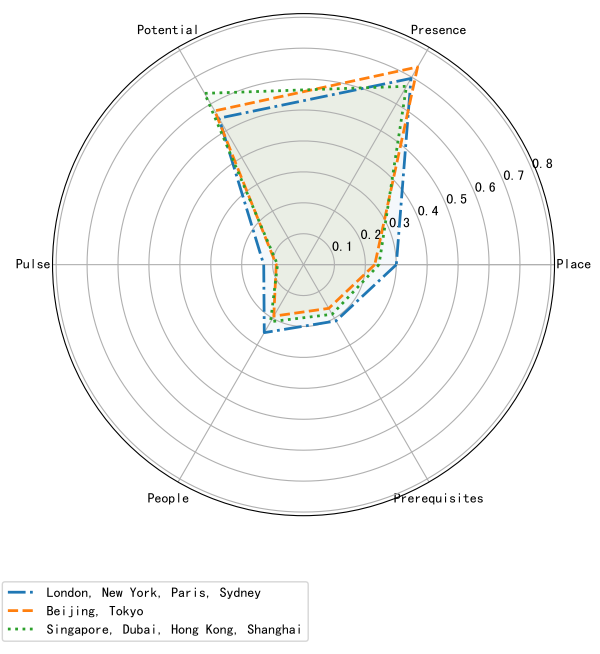

(b)

Figure 4. Dimensional Structures of City Brand Influence. (a) Dimensional Structures of Global Cities (b) Dimensional Structures of Cluster Centers.

Table 7. One-way ANOVA of City Brand Influence Dimensions.

\begin{tabular}{ccccc}
\hline & sum_sq & df & F & PR(>F) \\
\hline C(Dimension) & 0.205058 & 5.0 & 3.992496 & 0.003734 \\
Residual & 0.554698 & 54.0 & & \\
\hline
\end{tabular}

After performing the 12-norm-based normalization on the six-dimensional vectors of city brand influence for each global city and applying the K-Means algorithm to the corresponding normalized unit vectors, ten global cities are automatically divided into three clusters based on their structural characteristics captured by the unit vectors. The best $\mathrm{K}$ (the number of clusters) is 3 and the sum of squared distances to the closest cluster center (inertia) is 0.017. Cluster 1 contains London, New York, Paris, and Sydney; cluster 2 contains Beijing and Tokyo; and, cluster 3 contains Singapore, Dubai, Hong Kong, and Shanghai.

The structural characteristics of city brand influence clusters are captured by the unit vectors of cluster centers (Figure 4b): (1) the global cities in cluster 1 have relatively higher normalized values in the city brand influence dimensions of place, people, prerequisites, and pulse; (2) the global cities in cluster 2 have relatively higher normalized values in the city brand influence dimension of presence; and, (3) the global cities in cluster 3 have relatively higher normalized values in the city brand influence dimension of potential.

\section{Conclusions and Discussion}

The study adopted the research paradigm of computational social science and conducted theory-driven (city branding), data-driven (Google GDELT global news knowledge graph), and technology-driven (unsupervised machine learning) cross-disciplinary research in order to assess and compare the city brand attention, positivity, and influence, along with the dimensional structures of ten GaWC Alpha+ global cities projected by the global news media.

In terms of research materials (i.e., data collection), this study collected the big data of the GDELT global news knowledge graph, which covers the full-sample of cross-region, full-time (24/7), and multi-language global news articles related to ten global cities from 2017 to 2019. In terms of research method (i.e., data analysis), this study constructed an intelligent transforming and 
mapping method from the related GKG records to the city brand influence of global cities. From the theoretical perspective, this research method was built upon the theoretical framework of combining the cognitive and affective components of city brands, along with Anholt's global city brand dimension system. From the technological perspective, this research method was implemented by performing word-embedding semantic mining and clustering analysis on the related GKG records that are based on the artificial intelligence technique of unsupervised machine learning.

In this study, comparative analysis of the overall and dimensional values of global city brands, along with their individual and cluster structural characteristics, were performed. The comprehensive conclusions on the global city brands of London, New York, Paris, Singapore, Tokyo, Hong Kong, Shanghai, Dubai, Beijing, and Sydney projected by the global news media are summarized, as follows:

(1) The city brand influence of ten global cities forms distinct levels and clusters.

Based on the overall values of the city brand influence of each city, ten global cities are ranked in descending order as follows: New York, London, Paris, Beijing, Singapore, Dubai, Sydney, Hong Kong, Tokyo, and Shanghai. Based on the overall and normalized six-dimensional values of city brand influence, these ten global cities form distinct levels and clusters, respectively.

From the perspective of overall city brand influence, three distinct levels of global cities are formed. The first level consists of New York and London; the second level consists of Paris, Beijing, and Singapore; and the third level consists of Dubai, Sydney, Hong Kong, Tokyo, and Shanghai. From the perspective of similar structural characteristics of city brand influence, three distinct clusters of global cities are formed. The first cluster consists of New York, London, Paris, and Sydney; the second cluster consists of Beijing and Tokyo; and, the third cluster consists of Singapore, Dubai, Hong Kong, and Shanghai, as detailed below.

- The dimensional structures of global cities in the first cluster have higher normalized values in the city brand influence dimensions of place, people, prerequisites, and pulse. This indicates that along with the common structural characteristic shared by global cities, New York, London, Paris, and Sydney have more city brand influence in the quality of living, the prerequisites for development, and the "life" aspect of the "work-life" combination for people.

- The dimensional structures of global cities in the second cluster have higher normalized values in the city brand influence dimension of presence. This indicates that along with the common structural characteristic shared by global cities, Beijing and Tokyo, have a growing city brand influence in terms of global awareness and global contributions.

- The dimensional structures of global cities in the third cluster have higher normalized values in the city brand influence dimension of potential. This indicates that along with the common structural characteristic shared by global cities, Singapore, Dubai, Hong Kong, and Shanghai have more city brand influence in terms of opportunities for development and the "work" aspect in the "work-life" combination for people.

(2) Global cities share a common structural characteristic of city brand influence.

The six-dimensional structures of city brand influence of ten global cities follow a similar pattern:

- The city brand influence dimensions of presence and potential are the highest of all dimensions. These two dimensions represent the city's global status, standing, and contributions, along with the opportunities for development. In fact, high values of presence and potential within city brand influence is the most prominent characteristic of the ten global cities.

- The city brand influence dimensions of place, people, and prerequisites are medium across dimensions. These three dimensions represent the quality of living and the prerequisites for development of cities. The dimensions of place and prerequisites represent the "hard conditions" for life and development, while the dimension of people represents the "soft conditions" of cultural diversity, friendliness, and safety. For the ten global cities, although the values of these three dimensions are not the most prominent, they are still relatively strong. 
- The city brand influence dimension of pulse is the lowest among all dimensions. This dimension represents the advanced requirements of "soft conditions," i.e., finding interesting and exciting things to do in leisure time. For the ten global cities, this dimension is relatively insignificant.

(3) Western and Eastern global cities differentiate in the clustering of dimensional structures of city brand attention, positivity, and influence.

In the clustering of dimensional structures of city brand attention, positivity, and influence among global cities, New York, London, Paris, and Sydney are always in the same cluster. They are the global cities of the west and they have consistent and coherent structural characteristics in the clustering of city brand attention, positivity, and influence.

Global cities of the east (i.e., middle east, far east, and southeast Asia) vary in the clustering of dimensional structures of city brand attention, positivity, and influence.

- In the clustering of dimensional structures of city brand attention, all of the global cities in the east are in the same cluster.

- In the clustering of dimensional structures of city brand positivity, Tokyo and Hong Kong are in the same cluster as four western cities; Dubai, which is the global city in the middle east, forms a cluster itself; Beijing, Singapore, and Shanghai, which are global cities in the east with Mandarin as their native language, are in the same cluster.

- In the clustering of dimensional structures of city brand influence, Beijing and Tokyo, capital global cities in the far east, are in the same cluster; while the rest of global cities in east Asia (i.e., Singapore, Hong Kong, and Shanghai), along with Dubai, form the other cluster of global cities in the east.

The city brand attention, positivity, and influence of global cities are constructed based on the projection from global news media image and assessed through unsupervised machine learning based semantic mining and clustering analysis on big data from the GDELT global news knowledge graph. The above conclusions not only unearth the very essence of these ten global cities, but also shed a light on discovering the cognitive and affective preferences of global news media toward these cities. Specifically, the empirical results of city brand attention primarily reflect the cognitive preferences, while the empirical results of city brand positivity primarily reflect the affective preferences. Additionally, the empirical results of city brand influence reflect how the cognitive and affective preferences are merged. We discuss the following implications of these preferences in an attempt to provide references for global city branding practice:

(1) Compared to city brand positivity, city brand attention is more important for improving the city brand influence of global cities.

As shown in the empirical results, the city brand influence of global cities is mainly determined by the city brand attention. In other words, the impact of city brand positivity on the city brand influence of global cities is much smaller. This affects not only the overall values, but also the dimensional structures of city brand influence. The difference in impact is due to the city brand influence being the product of corresponding city brand attention and positivity, the degree of variation of city brand attention being much higher than the degree of variation of city brand positivity, and the following three main characteristics of city brand positivity of global cities.

- The overall and dimensional values of global city positivity are all smaller than 1 . This indicates the corresponding sum of negative emotion accumulations of global news articles is higher than the positive emotion accumulations. In other words, news media usually takes a critical view and focuses on the negative aspects of the cities. Additionally, the news audience is likely to pay more attention to the negative news, which also reinforces the negative preferences of global news media. This is consistent with findings in the previous literature [51,52]. 
- The differences among different dimensions of city brand positivity are not highly significant. This indicates that values of different dimensions of city brand positivity are at nearly the same level. For each global city, if one dimension of city brand positivity is high, then the rest of the dimensions are also high, and vice versa. It would be hard to significantly improve just a small subset of dimensions without improving the rest of the dimensions, and vice versa.

- The differences among the overall values of city brand positivity of different global cities are small. According to the empirical results, there is a mild negative correlation between the city brand attention and city brand positivity, while the positive correlation between the city brand attention and city brand influence is much stronger. This indicates that, although improving the city brand attention of a global city (for example, improving the number of related global news articles) may bring a limited reduction in the city brand positivity, the corresponding improvement in city brand influence might be considerable.

(2) The preferences of global news media over global city brands fits the nature of global cities.

According to the conceptualization by Sassen [1] and the operationalization by Beaverstock et al. [2], global cities are the command centers of the world economy, the driving force in the strategic transnational network of cross-border dynamics, and the central nodes of global networks of producer services. Being influential and production/development-oriented is the nature of global cities. Additionally, as shown in the empirical results, global news media pays a great amount of attention to the global city brands that fit this nature. The preference structure of global news media over global cities is as follows:

- Global cities that are more influential both internationally and domestically gain more attention from the global news media. On the one hand, the city brand attention and the city brand influence of New York and London are much higher than those of other global cities. They are also the two most internationally influential cities in the GaWC ranking system, They are at the level of Alpha++, while other global cities are at the level of Alpha+. Global media pays more attention to these two internally influential global cities. On the other hand, the first and second levels of overall values of city brand influence of global cities mostly consist of capitals, while the third level mostly consists of global cities that are not capitals. Capitals are more domestically influential, and global media pays more attention to them as well.

- City brand dimensions that are more relevant to production and development gain more attention from the global news media. The common structural characteristic of city brand influence shows that global news media pays much more attention to the dimensions of presence and potential than other dimensions. These two dimensions represent the core functions of production and development of global cities (i.e., the global contributions, the economic and educational opportunities, and so on), while the rest of dimensions (i.e., place, prerequisites, people, and pulse) are more about the development prerequisites and living conditions for people in global cities.

One key contribution of this study is the construction of a word-embedding semantic mining solution for assessing the city brands of global cities through transforming and mapping from the big data of the GDELT global news knowledge graph. The academic and practical value are mainly reflected in the following three aspects: (1) the city branding theory-based projection from the media image of global cities constructed by global news media to global city brands; (2) the computational social science research method of unsupervised learning based semantic mining and clustering analysis on the big data of global knowledge graph; and, (3) the construction of concepts of city brand attention, city brand positivity, and city brand influence, along with their relationships and the roles in assessing the city brands of global cities.

Admittedly, the city brand influence of global cities in this study is only assessed based on the media image constructed by the global news media. In other words, the conclusions are made from the perspective of global news media's presentation of global cities. Although the global news media 
is a major force in constructing global city brands and the full-sample big data of related global news articles mostly captures the objective nature of global cities, there are still other constructors of global city brands other than the global news media. Being unable to assess the global city brands from the perspectives of these constructors is the limitation of this study.

In future research, we will move from assessing the global city brands based on the global media image of global cities to assessing the global news media itself based on the theories of framing and agenda-setting, using the research paradigm of computational social science.

Author Contributions: All authors contributed to all parts of the paper equally. All authors have read and agreed to the submitted version of the manuscript.

Funding: This research was funded by Shanghai Philosophy and Social Science Research Project "A Study on Shanghai's Global City Brand Competitiveness, Evolution, and Improvement Strategies based on Word-Embedding Semantic Mining on the Big Data of the GDELT Global News", grant number 2019EXW007.

Conflicts of Interest: The authors declare no conflict of interest.

\section{References}

1. Sassen, S. The Global City: New York, London, Tokyo; Princeton University Press: Princeton, NJ, USA, 1991.

2. Beaverstock, J.V.; Smith, R.G.; Taylor, P.J. A roster of world cities. Cities 1999, 16, 445-458. [CrossRef]

3. GaWC. The World according to GaWC. 2018. Available online: https://www.lboro.ac.uk/gawc/ gawcworlds.html (accessed on 15 June 2020).

4. Gertner, D. Unfolding and configuring two decades of research and publications on place marketing and place branding. Place Branding Public Dipl. 2011, 7, 91-106. [CrossRef]

5. Zenker, S.; Martin, N. Measuring success in place marketing and branding. Place Brand. Public Dipl. 2011, 7, 32-41. [CrossRef]

6. Kavaratzis, M. From city marketing to city branding: Towards a theoretical framework for developing city brands. Place Brand. 2004, 1, 58-73. [CrossRef]

7. Sáez, L.; Periáñez, I.; Mediano, L. Building brand value in major Spanish cities: an analysis through municipal websites. J. Place Manag. Dev. 2013, 6, 120-143. [CrossRef]

8. Hernandez, J.; Lopez, C. Is there a role for informal settlements in branding cities? J. Place Manag. Dev. 2011, 4, 93-109. [CrossRef]

9. Hospers, G.J. Making sense of place: from cold to warm city marketing. J. Place Manag. Dev. 2010, 3, 182-193. [CrossRef]

10. Glińska, E.; Rudolf, W. City Brand Personality Projected by Municipalities from Central and Eastern Europe Countries-A Comparison of Facebook Usage. Sustainability 2019, 11, 5440. [CrossRef]

11. Won, J.; Lee, J.Y.; Jun, J.W. Influences of SNS (Social Network Service) Uses and Musical Consumption on City Branding: A Focus on Broadway, New York and the West End, London. Sustainability 2020, 12, 3856. [CrossRef]

12. Han, M.; de Jong, M.; Cui, Z.; Xu, L.; Lu, H.; Sun, B. City Branding in China's Northeastern Region: How Do Cities Reposition Themselves When Facing Industrial Decline and Ecological Modernization? Sustainability 2018, 10, 102. [CrossRef]

13. Oguztimur, S.; Akturan, U. Synthesis of City Branding Literature (1988-2014) as a Research Domain. Int. J. Tour. Res. 2016, 18, 357-372. [CrossRef]

14. Avraham, E. Cities and their news media images. Cities 2000, 17, 363-370. [CrossRef]

15. Green, A.; Grace, D.; Perkins, H. City branding research and practice: An integrative review. J. Brand Manag. 2016, 23, 252-272. [CrossRef]

16. Iglesias, O.; Ind, N.; Alfaro, M. The organic view of the brand: A brand value co-creation model. J. Brand Manag. 2013, 20, 670-688. [CrossRef]

17. Blichfeldt, B.S. Unmanageable place brands? Place Brand. 2005, 1, 388-401. [CrossRef]

18. Braun, E. History Matters: The Path Dependency of Place Brands. In International Place Branding Yearbook 2011: Managing Reputational Risk; Go, F.M., Govers, R., Eds.; International Place Branding Yearbook 2011: Managing Reputational Risk; Palgrave Macmillan: London, UK, 2011; pp. 39-46.

19. Aitken, R.; Campelo, A. The four Rs of place branding. J. Mark. Manag. 2011, 27, 913-933. [CrossRef] 
20. Papadopoulos, N.; Heslop, L. Country equity and country branding: Problems and prospects. J. Brand Manag. 2002, 9, 294-314. [CrossRef]

21. Ashworth, G.J. The Instruments of Place Branding: How is it Done? Eur. Spatial Res. Policy 2009. [CrossRef]

22. Xue, K.; Chen, X.; Yu, M. Can the World Expo change a city's image through foreign media reports? Public Relat. Rev. 2012, 38, 746-754. [CrossRef]

23. Hornskov, S.B. On the management of authenticity: Culture in the place branding of Øresund. Place Branding Public Dipl. 2007, 3, 317-331. [CrossRef]

24. Giovanardi, M.; Lucarelli, A.; Pasquinelli, C. Towards brand ecology: An analytical semiotic framework for interpreting the emergence of place brands. Mark. Theory 2013, 13, 365-383. [CrossRef]

25. Freeman, B.C.; Nhung Nguyen, T. Seeing Singapore: Portrayal of the city-state in global print media. Place Branding Public Dipl. 2012, 8, 158-169. [CrossRef]

26. Anholt, S. The Anholt-GMI city brands index: How the world sees the world's cities. Place Brand. Public Dipl. 2006, 2, 18-31. [CrossRef]

27. Popescu, R.I.; Corbos, A. Brand, Branding and Strategic Development. Amsterdam, Model for Bucharest. Adm. Public Manag. 2010, 14, 184-204.

28. Hankinson, G. The brand images of tourism destinations: a study of the saliency of organic images. J. Prod. Brand Manag. 2004, 13, 6-14. [CrossRef]

29. Zenker, S. Who's your target? The creative class as a target group for place branding. J. Place Manag. Dev. 2009, 2, 23-32. [CrossRef]

30. Lucarelli, A. Unraveling the complexity of "city brand equity": A three dimensional framework. J. Place Manag. Dev. 2012, 5, 231-252. [CrossRef]

31. Demirbag, K.M.; Yurt, O.; Guneri, B.; Kurtulus, K. Branding places: applying brand personality concept to cities. Eur. J. Mark. 2010, 44, 1286-1304. [CrossRef]

32. Tugulea, O. City Brand Personality-Relations with Dimensions and Dimensions Inter-Relations. Sustainability 2017, 9, 2243. [CrossRef]

33. Gilboa, S.; Jaffe, E.D.; Vianelli, D.; Pastore, A.; Herstein, R. A summated rating scale for measuring city image. Cities 2015, 44, 50-59. [CrossRef]

34. Luque-Martinez, T.; Del Barrio-García, S.; Ibanez-Zapata, J.A.; Molina, M.Á.R. Modeling a city’s image: The case of Granada. Cities 2007, 24, 335-352. [CrossRef]

35. Pike, S. Destination brand positions of a competitive set of near-home destinations. Tour. Manag. 2009, 30, 857-866. [CrossRef]

36. Qu, H.; Kim, L.H.; Im, H.H. A model of destination branding: Integrating the concepts of the branding and destination image. Tour. Manag. 2011, 32, 465-476. [CrossRef]

37. Vuignier, R. Place branding and place marketing 1976-2016: A multidisciplinary literature review. Int. Rev. Public Nonprofit Mark. 2017, 14, 447-473. [CrossRef]

38. Lazer, D.; Pentland, A.; Adamic, L.; Aral, S.; Barabasi, A.L.; Brewer, D.; Christakis, N.; Contractor, N.; Fowler, J.; Gutmann, M.; et al. Life in the network: The coming age of computational social science. Science 2009, 323, 721-723. [CrossRef]

39. Richens, R.H. Preprogramming for mechanical translation. Mech. Transl. 1956, 3, $20-25$.

40. Singhal, A. Introducing the Knowledge Graph: Things, Not Strings. 2012. Available online: https://www. blog.google/products/search/introducing-knowledge-graph-things-not/ (accessed on 15 June 2020).

41. Leetaru, K.; Schrodt, P.A. GDELT: Global Data on Events, Location and Tone. In Proceedings of the Annual Meeting of the International Studies Association, San Francisco, CA, USA, 3-6 April 2013.

42. Guo, L.; Vargo, C.J. Global Intermedia Agenda Setting: A Big Data Analysis of International News Flow. J. Commun. 2017, 67, 499-520. [CrossRef]

43. Vargo, C.J.; Guo, L.; Amazeen, M.A. The agenda-setting power of fake news: A big data analysis of the online media landscape from 2014 to 2016. New Media Soc. 2017, 20, 2028-2049. [CrossRef]

44. Hopp, F.R.; Schaffer, J.A.; Fisher, J.T.; Weber, R. iCoRe: The GDELT Interface for the Advancement of Communication Research. Comput. Commun. Res. 2019, 1, 13-44. [CrossRef]

45. Mikolov, T.; Sutskever, I.; Chen, K.; Corrado, G.; Dean, J. Distributed Representations of Words and Phrases and their Compositionality. Adv. Neural Inf. Proc. Syst. 2013, 26, 3111-3119.

46. Caliskan, A.; Bryson, J.J.; Narayanan, A. Semantics derived automatically from language corpora contain human-like biases. Science 2017, 356, 183-186. [CrossRef] [PubMed] 
47. Garg, N.; Schiebinger, L.; Jurafsky, D.; Zou, J. Word embeddings quantify 100 years of gender and ethnic stereotypes. Proc. Natl. Acad. Sci. USA 2018, 115, E3635. [CrossRef] [PubMed]

48. Kozlowski, A.C.; Taddy, M.; Evans, J.A. The Geometry of Culture: Analyzing the Meanings of Class through Word Embeddings. Am. Sociol. Rev. 2019, 84, 905-949. [CrossRef]

49. Garten, J.; Hoover, J.; Johnson, K.M.; Boghrati, R.; Iskiwitch, C.; Dehghani, M. Dictionaries and distributions: Combining expert knowledge and large scale textual data content analysis. Behav. Res. Methods 2018, 50, 344-361. [CrossRef] [PubMed]

50. Arthur, D.; Vassilvitskii, S. K-Means++: The advantages of careful seeding. In Proceedings of the Eighteenth Annual ACM-SIAM Symposium on Discrete Algorithms, New Orleans, Louisiana, 7-9 January 2007; Society for Industrial and Applied Mathematics: Philadelphia, PA, USA, 2007; pp. 1027-1035.

51. Kim, J.Y.; Kiousis, S. The Role of Affect in Agenda Building for Public Relations: Implications for Public Relations Outcomes. J. Mass Commun. Q. 2012, 89, 657-676. [CrossRef]

52. Nabi, R.L. Exploring the Framing Effects of Emotion: Do Discrete Emotions Differentially Influence Information Accessibility, Information Seeking, and Policy Preference? Commun. Res. 2003, 30, $224-247$. [CrossRef]

(C) 2020 by the authors. Licensee MDPI, Basel, Switzerland. This article is an open access article distributed under the terms and conditions of the Creative Commons Attribution (CC BY) license (http://creativecommons.org/licenses/by/4.0/). 